\title{
El sujeto disperso en los diarios de Alejandra Pizarnik y las fuerzas de lo verosímil ${ }^{1}$
}

\section{Resumen}

\author{
Santiago Hamelau \\ Licenciado \\ Universidad Católica Argentina \\ https://orcid.org/0000-0001-7461-445X \\ santiagohamelau@gmail.com
}

A través de su diario íntimo, la poeta Alejandra Pizarnik ha construido un sujeto que puede caracterizarse como inestable, marginal e incompleto. Esta falta de límites bien definidos nos ha llevado a nombrarlo "sujeto disperso», es decir, una identidad lábil que adopta diferentes formas, cuya extensión nunca es del todo conocida, pero que, a pesar de esto, se mantiene cohesionada. El análisis propone deslindar cuatro operaciones gramaticales y tres figuras de la otredad a través de las cuales la voz del discurso erige su subjetividad. Al mismo tiempo, se busca explicar los lazos que mantienen unida esta materia dispersa.

Palabras clave: diario íntimo; otredad; Pizarnik; subjetividad; sujeto disperso.

\section{The Scattered Subject in Hlejandra Pizarnik's Diaries and the Forces of Verisimilitude}

\section{Hbstract}

The poet Alejandra Pizarnik has built a subject through her journal that can be described as unstable, incomplete and habiting the margins. Its lack of clear boundaries has inclined us to name it "scattered subject", meaning a labile identity that can adopt different forms, whose extension is never fully known, but that is, in spite of everything, capable of cohesion. Our analysis attempts to define four grammatical operations and three figures of otherness through

\footnotetext{
${ }_{1}^{1}$ Procedencia del artículo: Este artículo es resultado de mi presente investigación sobre diaristas íntimos del Cono Sur. Agradezco los comentarios y correcciones de mi director, así como de la Dr. María Lucía Puppo y de la Dr. María José Punte.
} 
which the voice of discourse erects her subjectivity. Concurrently, we seek to find an explanation for the ties that hold together a matter in dispersion.

Keywords: intimate diaries; otherness; Pizarnik; scattered subject; subjectivity.

Recibido: 14 de abril del 2021. Hprobado: 24 de mayo del 2021

Artículo de reflexión

https://doi.org/10.25100/poligramas.v0i53.11588

\section{¿Cómo citar este artículo en MLA? - How to quote this article in MLA?}

Hamelau, Santiago. "El sujeto disperso en los diarios de Alejandra Pizarnik y las fuerzas de lo verosímil" Poligramas 53 (2021): e.2511588 Web. Fecha de acceso (día, mes en mayúscula y abreviado, y año).

Man is least himself when he talks in his own person. Give him a mask and he will tell you the truth.

Oscar Wilde, The Critic as Artist

\section{El diario y la dispersión}

Como sostiene Nora Catelli, la conservación de los papeles íntimos de Alejandra Pizarnik marca la aparición de un nuevo campo de trabajo. Lleno de potencial para la crítica autobiográfica y los estudios de la intimidad, el diario de Pizarnik pone de manifiesto las complejidades que surgen para el yo cuando este funciona a la vez como sujeto y objeto del lenguaje (Invitados al palacio 5). La identificación entre subjetividad y lenguaje se evidencia del todo problemática. “¿Quién es el yo? Esto no lleva a nada porque el yo no existe” (Diarios 286), escribe Pizarnik el 6 de noviembre de 1962. Esto parece esperable si consideramos que, como argumenta César Aira siguiendo a Lacan, todo intento de coincidencia entre el yo y la palabra "yo» está destinado al fracaso, debido a que "el sujeto del enunciado es una máscara, infinitamente variada, del sujeto de la enunciación" (60). 
Una de las cualidades más representativas de la escritura de Alejandra Pizarnik es la fragmentariedad. Los académicos que han estudiado el diario han hecho hincapié en ese aspecto. Federica Rocco apunta el tema del doble, los desdoblamientos del sujeto y el estallido de voces dentro del texto (...El loco afán... 204). Asimismo, López y Encinas entienden la fragmentariedad como un principio estético de organización del material -la vida- que guarda relación con las formas de escritura limítrofes e inconclusas del romanticismo y las vanguardias (163). Violeta Percia, de igual forma, reconoce en el sujeto Pizarnik construido por el diario un yo fragmentado (87). Por último, Buenaventura, Barredo y Oller, que condujeron un estudio informatizado de los diarios, analizaron el sujeto de Pizarnik sobre la base de la terminología de Deleuze como puro devenir y concluyeron que la huida del sujeto del presente generaba identidades infinitas (243).

Por otra parte, la fragmentariedad está en relación directa con el género que nos proponemos examinar. Como señaló tempranamente Maurice Blanchot, el diario íntimo suele aparecer "desprendido de las formas, [...] dócil ante los movimientos de la vida" (207). En efecto, un rasgo paradójico del género es que permite cualquier configuración. Así, es posible encontrar en las páginas de un diario anécdotas, poemas, dibujos, una frase que le ha gustado a quien anotaba, un nombre suelto, un objeto pegado que guarda relación con el momento de escritura. Mayte Cantero Sánchez también entiende la temporalidad como un elemento que vuelve al fragmento una necesidad de base dentro del género (218). Rocco comenta, además, cómo la escritura au jour le jour se manifiesta "equívoca", por cuanto carece de una visión panorámica sobre el tema en cuestión, es decir, la vida en progreso del escritor (Errancia y nomadismo... 203).

El carácter desarticulado del diario llevó a Barthes a pensar que, en lugar de un libro o una obra, este era más bien un álbum, cuyos elementos internos podían permutarse e incluso suprimirse, sin que la totalidad se viera afectada. Desde su visión de la literatura, el diario era un género menor, cuyo valor no podía parangonarse al de la novela, por ejemplo, ni en términos de esfuerzo ni de calidad literaria. En 1986, Phillipe Lejeune volvió la atención sobre el diario y buscó entenderlo desde sus lógicas internas. Ya en su famoso ensayo "El pacto autobiográfico" había definido la autobiografía como: "[r] elato retrospectivo en prosa que una persona real hace de su propia existencia, poniendo énfasis en su vida individual y, en particular, en la historia de su personalidad" (48), al mismo tiempo que deslindaba el diario íntimo como aquel género 
vecino que no cumplía con la perspectiva retrospectiva de la narración. Más tarde, Lejeune definió al diario íntimo como una "serie de rastros datados" (On Diary 179, traducción propia), con lo que postula nuevamente la idea de fragmentos articulados, pero pone en el centro la cuestión de la subjetividad. Los fragmentos importan y se rescatan porque son rastros de una subjetividad. Ellos adquieren una estructura que tiene su origen en esa subjetividad y que se exterioriza gracias a la datación, esto es, a la inscripción de los acontecimientos dentro del tiempo establecido por la comunidad o, más precisamente, dentro del encuentro entre el tiempo universalizado -macrotemporalidad-y el tiempo vital del sujeto -microtemporalidad-.

Muchos diarios, incluso si solo son publicados póstumamente -costumbre ya en decadencia- pueden haber sido escritos con la intención de ser publicados. De Pizarnik, que parece pertenecer a esta lista, podríamos decir, junto con Leonor Arfuch, que representa con su diario "lo íntimo en lo público, [el] espectáculo de la interioridad" (110). La poeta argentina, que nace bajo el nombre administrativo de Flora, decide en la adolescencia darse el de Alejandra tanto en el ámbito público como privado. Antes incluso de escribir poesía, según conjetura Rocco, empieza un diario (Alejandra Pizarnik... 82). Una hipótesis que no ocupará estas páginas podría plantear la vecindad entre ambos géneros. Todos los libros de Pizarnik, con excepción de La tierra más lejana-obra de la que después reniega- están publicados bajo el nombre "Alejandra Pizarnik». Así también firma cartas a sus amigos o a su psicoanalista. De algún modo, Pizarnik se nace a ella misma (Rocco, ... Mujeres en el umbral... 109) y el diario registra este proceso. Solo el primer cuadernillo que forma parte de su obra diarística tiene al frente escrito "flora alejandra pizarnik". Luego el yo, tanto en portadas de cuadernillos como al interior del texto, hará referencia al alter ego Alejandra, asumido como nuevo nombre.

La creación de un sujeto del enunciado -Flora/Alejandra Pizarnik- por parte de un sujeto de la enunciación - de nuevo, Flora/Alejandra Pizarnik- está relacionada, en primer lugar, con la tesis sostenida por Julio Premat de que toda literatura creada por un autor aparece en paralelo al nacimiento de una figura de autor (12). Los escritores diaristas se preguntan cómo serán leídos, qué conclusiones sacarán de toda su obra, la pública y la privada. La advertencia de Alberto Giordano parece justa: todo autor se desliza cuesta abajo de la pendiente constituida por "las posibilidades y los riesgos de la auto-figuración" (709). Además, el sujeto dentro del diario surge como resultado de intentar narrar la propia vida. Mientras estudiaba la novela, Mijaíl Bajtín dictaminó que era imposible ser uno mismo y hablar de uno mismo: "yo para mí soy 
estéticamente irreal" (161). Por lo tanto, el sujeto, al intentar definirse, vive en un perpetuo estado de crisis (En la era de la intimidad 41), como expresa Catelli, ya que la palabra que lo revela es la misma que no lo deja aprehenderse.

Leonor Arfuch menciona la interpretación lacaniana del diario propuesta por Catelli como una posición femenina y comenta: "Más que un género es una situación (un encierro) de escritura" (112). Escribir un diario implica, en cierto modo, un abandono de la sociedad masculina y productiva. Mientras que el diario podría ser así fácilmente asociado con una pérdida de tiempo, en realidad este da forma a un mundo de incertidumbres conectadas con el miedo y la autorrepresentación, que de otra manera permanecerían invisibles o escondidas en los aposentos de la intimidad. Así, el diario se vuelve una purga, una lucha contra el miedo, un mecanismo de protección. El género, como expresa Lejeune (On Diary 53), encarna una tradición que data de la antigua Grecia y que está vinculada con un olvidado precepto órfico: "cuidado de sí" (Foucault 50).

Retomando la noción de fragmentariedad en el diario, sostenemos que la forma en que aquella es promovida y articulada conviene a la comunicación de la subjetividad como alteridad. La escritura, espejo al que asiste cotidianamente el sujeto a intervalos mínimos o considerables, fija en cada instancia un momento de ese fluir evanescente de la subjetividad que no se encuentra substanciada de antemano o definida a priori, sino que es maleable al paso del tiempo y a la fuerza de la otredad. No obstante, el misterio sigue vigente, pues, pese a la indeterminación de la identidad, la subjetividad puede aún reconocerse en dos rasgos inalienables e irreproducibles: su voz y su historia. La primera aparece en el diario articulada en torno a la primera persona del singular; la segunda la encontramos en la seguidilla de entradas, así sea esta sincera o el resultado de un embuste consciente.

Paul Ricoeur estableció en la ipseidad el contrapunto necesario del sí mismo, como otredad constituyente del sujeto (XIII). Es decir, nos llevó a comprender que la subjetividad nunca está sola o, de otro modo, no sería consciente de ella misma. Resuena, sin lugar a dudas, la sentencia de Emile Benveniste: "La instalación de la 'subjetividad' en el lenguaje crea, en el lenguaje y -creemos- fuera de él también, la categoría de persona" (184). El lenguaje, como entidad dialogal, significa necesariamente la apertura del sujeto hacia el otro y, con ese acto, la cofundación de ambas personas. El diario, que podría parecer un largo soliloquio, en realidad es un género dialogado del sí mismo con sus otros, los cuales serán imprescindibles para 
cualquier intento de definición de esa subjetividad en construcción o, como han popularizado las artes plásticas, in progress.

El propósito de este artículo es analizar y describir la representación que Pizarnik hace de ella misma dentro de su diario íntimo, en relación con las posibilidades específicas permitidas por el género. Para ello, se utilizarán categorías provenientes de distintos ámbitos: la gramática, el análisis del discurso y la semiología. Al respecto, serán de utilidad las hipótesis y teorizaciones de Julia Kristeva, Paul De Man y Dominique Maingueneau. Para describir la subjetividad construida por la poeta argentina a través de la voz de su diario íntimo, se tendrá en cuenta los presupuestos ya estipulados: 1. la fragmentariedad como característica específica de la literatura de Alejandra Pizarnik, 2. la subjetividad no atada a un contenido inamovible y 3. la fragmentariedad como característica genérica del diario y espejo de la fluidez de la subjetividad. Esto se traducirá en nuestro análisis en un criterio de definición difusa: ya que el sujeto es inaprensible como totalidad, pues no puede definirse mediante la precisión conceptual, se definirá por medio de la sumatoria de momentos, de planos y de perspectivas.

El yo en Pizarnik se encuentra dislocado, empujado hacia fuera de sus límites, multiplicado y rearticulado dentro de la prosa diarística. La deixis es la categoría gramatical que rige el ejercicio de dislocación y pone en acto los siguientes cuatro procedimientos: 1. la alusión a la tercera persona, 2. la alusión a la segunda persona, 3. la dislocación en el tiempo y 4. la ambigüedad pronominal. Por otro lado, si se considera el plano del sentido, aparecen tres figuras de la otredad que contribuyen a elaborar la comprensión del «sujeto disperso»: 5. el espejo y el doble, 6. la dislocación entre el sujeto y su cuerpo o su voz, y 7. la extranjería. Desde ya, estos procedimientos y figuras se dan en el texto imbricados unos con otros. Finalmente, se buscará encontrar una explicación para esta heterogeneidad o dispersión del sujeto, que, no obstante, se encuentra contenida dentro de los límites del diario íntimo.

\section{Procedimientos de dislocación}

El primer mecanismo a analizar es la traslación de la primera persona gramatical a la tercera, es decir, de la persona que habla a aquella sobre la cual se habla. Este probablemente sea el más variado y complejo, puesto que admite una serie de realizaciones dentro del diario: el uso del nombre propio "Alejandra», de los pronombres indefinidos, de diversos personajes y del participio de pasado en función sustantiva. Esta enumeración se desarrollará por orden. 
En la entrada del martes 28 de octubre de 1957, asistimos a una interesante pantomima donde el sujeto, que nunca deja de representarse, se va trasladando de una persona a otra en sucesivas modulaciones. En un relato con fuertes reminiscencias de Ante la Ley de Kafka, nos encontramos con un sujeto femenino: "ella», cuyo nombre en un principio desconocemos, pero intuimos, que se arroja ante las puertas de la vida y la muerte, y espera ser salvada. Otra persona, que aparece diferenciada del sujeto femenino protagonista y de la voz narradora, es identificada como capaz de hacer efectiva esta salvación a través del acto de nombrar: "decirle Alejandra con un poco de calor en la voz" (Pizarnik, Diarios 197). Párrafo aparte, la primera persona recobra su preeminencia e invocando al Señor - ¿Dios?, ¿alter ego del guardián kafkiano? - se identifica como aquella capaz de salvar a la protagonista femenina, que, gracias al correlato biográfico, se deduce no puede ser otra que ella misma. La voz da entidad a sujetos que, pese a la confusión, acaban coincidiendo; son máscaras de Pizarnik. Luego, aparece una reflexión general que incluye al yo dentro de la colectividad del nosotros: la tragedia del hombre yace en el desconocimiento del otro, en la práctica del egoísmo perjudicial: "No importa que yo no vea el sol. Lo esencial es que tú no lo veas" (Pizarnik, Diarios 198). Vivimos, sostiene la voz diarística, en las sombras como producto de la falta de fraternidad, del quebrantamiento del vínculo con el prójimo. Ante esta inaccesibilidad del otro, el yo se cierra sobre sí mismo. El estado de espera descripto en el pasaje se parece a los estados místicos de angustia. Una emoción más terrena y filosófica suplanta el éxtasis y la unión con lo divino. Adviene el asombro: "Asombro de ser una muchacha en la noche preñada de augurios" (Pizarnik, Diarios 198). La descripción de Pizarnik de sí misma demuestra a una persona consciente de la identificación entre poeta y vate. La presencia de la noche es prueba de una herencia romántica invocada por la autora en la figura de Novalis, que había creído que en medio de la noche y de la ausencia el poeta podía instaurar el paraíso. En el caso de Pizarnik, la noche es el lugar donde se gesta la palabra poética, donde se reciben las visiones. En el diario, ella se describe leyendo con vehemencia, a veces sin comprender o sin gusto. Razona que, si los poemas están hechos de palabras, es necesario devorar cuantas se pueda antes de dormir. Alberga la ilusión de que encontrará poemas perfectamente confeccionados al cabo del sueño. La creación poética se halla vinculada con lo transterreno. Al mundo de los sentidos, el sujeto debe sumar el mundo del espíritu, con el propósito de acceder a esa zona oscura más allá de lo racional. No extraña que al final de la entrada leamos: "Cerrad los ojos de la cara y abrid los ojos del corazón" 
(Pizarnik, Diarios 198). Consecuentemente, ese otro anhelado y salvífico al que se hacía referencia antes adquiere una nueva valencia, podría tratarse de lo que Pizarnik no es en tanto que poeta, es decir, la inspiración o las musas, dispuestas a convidar o mezquinar la gracia de la escritura a este yo obsesionado con la producción y la posteridad.

El diario de Pizarnik se muestra como una larga escuela de aprendizaje: tanto del lenguaje como de ella. Quizás esto sea decir lo mismo: del lenguaje en sí que también es el lenguaje con el que ella sea capaz de nombrarse. Pizarnik se describe como una "estudiante" (Diarios 271). Frecuentemente, menciona lecturas que la forman, como El Quijote o los diarios de diversos autores -Kafka, Mansfield, Pavese, Woolf, etc.-, prueba de que conocía bien el género. También, refiere los poemas que está escribiendo y las dificultades que enfrenta para expresarse. Del diario de Du Bos extrae una definición de Dostoievski que se atribuye a sí misma, pero en tercera persona: "'un ser que durante toda su vida no vive, sino que no cesa de imaginarse a sí mismo.' He aquí Alejandra" (Pizarnik, Diarios 246). La cita recuerda las mismas críticas que Hénri-Frédéric Amiel (Lejeune, On Diary 149), Roland Barthes (1986) o Maurice Blanchot (1959) le hacían al diario, cuyo peligro residía en olvidarse de vivir, en reemplazar el tiempo del día por el tiempo de la literatura. Pizarnik parece ser una escritora especialmente sensible a las lógicas del género, en tanto que la persona biográfica proyectada por su diario es la de una escritora cuya vida era un sucedáneo o una página más de la literatura que inventaba en paralelo. El diario es una empresa exploratoria, un lento escrutinio de sí misma, al igual que un descenso, para emplear la retórica de Arthur Rimbaud. A través del deambular errático por los terrenos de la intimidad, la memoria, la culpa, el sufrimiento, el amor, el deseo, la espera, la salvación, Pizarnik intenta definirse. Ejerce el verbo gracias a la versatilidad del diario que permite todas las expresiones del yo: los monólogos interiores, el fluir de la conciencia, las preguntas retóricas y los relatos donde el yo se ficcionaliza -por partida doble, habría que decir, pues el diario ya supone una primera instancia de ficcionalización-.

Consideremos, por caso, la siguiente cita: “¿De dónde viene esta historia o historieta inarticulada? (De lo más profundo de su subconsciente, dice la famosa psicoanalista Alejandra P.)" (Pizarnik, Diarios 438). Ante la pregunta retórica por el origen de la historia o historieta inarticulada -que hace referencia a un texto inmediatamente anterior al fragmento citado del diario y por qué no también al diario mismo como devenir de escritura-, no hay contestación por parte del sujeto. En cambio, aparece consignada la respuesta entre paréntesis -el gesto no 
es menor, por cuanto aparta y encapsula el discurso, como si otra voz susurrara dentro de la voz del diario- y se atribuye a una Pizarnik disfrazada de psicoanalista. Lo que el discurso rompe y separa el nombre propio y el sentido común lo vuelven a compaginar. La narración de sí -el diario- no puede tener otro origen que Pizarnik, autora y sujeto diarístico a un mismo tiempo. Por otro lado, pese al alejamiento gramatical a través del cambio de persona y del pronombre "Su», que denota formalidad, la otra voz inventada entre paréntesis continúa siendo ese yo titánico del diario, conciencia todopoderosa y vigilante, que termina graciosamente por recibir el nombre de Alejandra P. Más allá de que el pasaje tenga un aire cómico (y corrosivo), la comparación con el psicoanálisis en el fondo revela lo que tal vez la autora pensaba o intuía que debía ser el diario -o lo que podía ser para ella-. Si el psicoanálisis confronta al paciente con un otro -el terapeuta- para que aquel se revele algo a sí mismo, entonces el diario es un ejercicio de observación minuciosa movido por un esperado y nunca completado desvelamiento del sí mismo en la figura del otro.

El uso de pronombres indefinidos muchas veces soluciona momentáneamente el acercamiento al misterio de la identidad y de lo íntimo. El proceso de nominar se intercambia por el de localizar: "no fantasear ni ser otras" (Pizarnik, Diarios 318) o "En mí hay alguien que acepta el mal y el sufrimiento del desorden" (Pizarnik, Diarios 591). En anteriores oportunidades, si bien se contaba con mayores precisiones del sujeto (un nombre, una descripción), la voz se planteaba como ilocalizable debido a los ropajes pronominales y a los cambios en las perspectivas de enunciación. Para los ejemplos citados en este párrafo, si bien podemos localizar al sujeto del enunciado a través de la primera persona del singular, ya no es posible definirlo, porque hay zonas de ese sujeto a donde la voz no llega. Ni las "otras» ni el «alguien» pueden hablar. En física cuántica, se denomina principio de indeterminación a la imposibilidad de medir simultáneamente, con absoluta precisión, dos magnitudes conjugadas. Si se conoce una de estas variables con absoluta exactitud, la otra se torna indiscernible. Schrödinger utilizó un gato, una caja y una ampolla de veneno para ejemplificar la realidad cuántica. Posteriormente, la metáfora del físico austriaco-irlandés tendrá más que decirnos al respecto del sujeto dentro del diario.

Permanecen aún sin comentario dos variantes del uso de la tercera persona. La primera se refiere a los participios de pasado pasivos en función sustantiva, de la cual se ofrece aquí una breve enumeración: "la canción de la quemada" (Pizarnik, Diarios 1074); "la tan sentada, 
la siempre sentada, en su sillón de espinas, yéndose por fin, al paso de sí misma, yéndose por fin y cayendo dentro de su propio espacio" (Pizarnik, Diarios 400); "Peligro de la ahogada" (Pizarnik, Diarios 417-418); "Pequeña alucinada por las calles sucias, buscando en cada rostro la presencia del que solo aun ausente; vagando lentamente entre las viejas mendigas -que me prefiguran-" (Pizarnik, Diarios 435). En todos los casos, el sujeto se encuentra definido no en su capacidad de actuar, sino de padecer alguna acción o estado que parece serle impuesto, incluso con violencia, como se observa en "la ahogada». Los participios y las imágenes tienen relación directa, como se advertirá, con el oficio de la escritura, concebido bajo el precepto de la norma romántica, inspirada o maldita. La poeta es un individuo sufriente - «sentada en su sillón de espinas»-, a la deriva -"yéndose»-, "ahogada» por la frustración expresiva, y solo por momentos capaz de captar - «alucinada»- el instante privilegiado, como querían los surrealistas. El 2 de febrero del año 1965 puede leerse: "Intento de definir el instante privilegiado. Imposible, pues para reconocerlo tendría que recortarse sobre una sucesión de días monótonos, dedicados a lo utilitario" (Pizarnik, Diarios 707).

El último ejemplo citado en la lista anterior, de la página 435, donde aparece "mendigas", avanza sobre la última variante en el uso de la tercera persona: la traslación o identificación del sujeto del diario con una serie de personajes femeninos, algunos de los cuales listamos a continuación: "mi situación de huérfana" (Pizarnik, Diarios 204); "Luchará la triste muchacha (...)?" (Pizarnik, Diarios 210); "la pequeña sonámbula" (Pizarnik, Diarios 391); "idiota enamorada del aire" (Pizarnik, Diarios 399); "Y no soy más que una silenciosa, una estatua corazón-mente enferma, una huérfana sordomuda, hija de algo que se arrodilla y de alguien que cae. Solo soy algo que está, algo que no espero que está" (Pizarnik, Diarios 403); "adentro razonan locas, adentro arrasan con todo" (Pizarnik, Diarios 1069). En todos los casos, se trata de personajes errantes, instalados en espacios marginales, amenazados por fuerzas más grandes que ellos y afectados por la desorientación.

Mariana Di Ció analiza la autorrepresentación del sujeto lírico en Árbol de Diana y cita personajes como los que encontramos en el diario (Paratopía, localización 2). Di Ció busca esclarecer o mínimamente llamar la atención sobre la voluntaria confusión entre el sujeto lírico y el sujeto biográfico. En nuestro caso, sujeto biográfico y sujeto autobiográfico-discursivo no pueden estar sino confundidos e imbricados: la imagen pegada a la realidad como una película difícil de advertir. El sujeto autobiográfico es una continua puesta en escena y 
autorrepresentación del sujeto biográfico. Los personajes recogidos en Árbol de Diana son interpretados por Di Ció como "avatares del escritor" (3) y el sujeto biográfico, gracias al discurso poético, queda asociado a "la figura del errante o nómada y la figura del poeta inspirado o escritor maldito" (3). Esta apreciación puede ser aplicable al discurso diarístico y a lo que sucede con los personajes femeninos enumerados en el anterior párrafo.

El segundo mecanismo gramatical es la alusión a la segunda persona, oficiada por un cambio pertinente en la forma verbal, que a veces puede estar acompañada del nombre propio. El efecto que produce la segunda persona puede ser el de un diálogo de la voz consigo misma o el de consejos, advertencias, admoniciones y reproches que la voz se dice a sí misma, en la forma de un tú, pero donde no hay intercambio. El siguiente es un ejemplo de diálogo:

Dentro se quema, se rompe, dices que me voy a desvanecer pero no es así, no es así, es sólo un súbito no poder hablar, un buscar a qué asirte porque algo, algo pronto no te deja. Qué cosa no te deja. Qué quisieras hacer que eso no te deja. Quisiera hablar, quisiera escribir, quisiera contarlo de manera que no se preste a confusiones (Pizarnik, Diarios 1067).

La voz vuelve real a la segunda persona del discurso cuando dentro de su enunciación escribe "dices» y recupera un discurso supuestamente previo, no consignado, para que el lector pueda reponer la elipsis hipotética. La repetición de «no es así» tiene una intención persuasiva que genera, a su vez, el efecto de una verdadera discusión. Los pronombres «te» de "asirte» y "no te deja» parecen asumir realizaciones generales, a la manera de una construcción impersonal. Las dos preguntas siguientes, parecidas en su contenido y franqueadas por puntos, se hallan dentro de una nueva enunciación: la del tú imaginario. El yo responde de inmediato: "Quisiera..... El cambio de la persona gramatical en el verbo traza el límite entre ambas enunciaciones y así logra verosimilizarse la situación ficticia del diálogo. La repetición tripartita del verbo con cambios en los infinitivos sugiere el tópico de la insistencia conectado con la plegaria. El recurso de la segunda persona produce, así, el efecto verosímil de una conversación personal de Pizarnik consigo misma o lo que Unamuno hubiera llamado monodiálogo.

Por otro lado, si bien el uso de la segunda persona siempre construye un diálogo ficticio, este puede no contar con la respuesta de una de las partes. Estamos ante la presencia de un sujeto que habla y otro que escucha. Eso genera cierta confusión acerca de quién habla y, en 
consecuencia, de dónde nos posicionamos como lectores. No es claro si la voz le dice algo a una "Alejandra" que es ella misma o si Alejandra escucha que una voz le dice algo. Si bien para el caso ambas son la misma, el lector debe instalarse de uno u otro lado, pues ya no puede cambiar de perspectiva según los cambios de la enunciación. El sujeto que habla cuenta con una posición más elevada, dado que tiene en su poder el discurso, a diferencia del sujeto que escucha. He aquí la causa de las tonalidades mencionadas: el consejo, la advertencia, la admonición y el reproche. "Tú no deseas nada, si bien esto no es verdad. Desearías morir. No mueres porque el sexo te importa todavía" (Pizarnik, Diarios 523).

El tercer submecanismo gramatical es la dislocación temporal. En reiteradas oportunidades, el cambio de tiempo verbal o el uso de ciertos verbos multiplica al sujeto que aun así pretende hacer coincidir en un único presente de enunciación dos momentos de sí separados en el tiempo. El lenguaje objetualiza al sujeto en diferentes estadios temporales y habilita una simultaneidad imposible en la realidad fáctica. La paradoja sobreviene por la contigüidad de los elementos en el discurso. Al tiempo que una realidad se instala, otra subsiguiente la desplaza de inmediato. Por ejemplo: "Quiero ser la que ya soy - dijo." (Pizarnik Diarios 230) y "Mi memoria vela el cadáver de la que fui" (Pizarnik, Diarios 1082). En el primer caso, se reproduce una situación discursiva pasada a través del verbo «dijo», con el que el sujeto se aleja en la tercera persona. Se superponen los sujetos del futuro-deseo y del presente y, al querer ser algo que ya se es, se obtiene un efecto paradójico. En el segundo caso, la coincidencia se da entre el yo que no es más, devenido cadáver, y el yo-presente que, en su ser otro, se sabe distinto de lo que fue. Ambas frases son en alguna medida una puesta en abismo de la enunciación del diario. Las anotaciones están atravesadas por el deseo de un sujeto que busca ser idéntico a quien escribe, pero acaba siendo el que nace en lo escrito; a su vez, cada entrada queda siempre relegada al pasado inmediato, con lo que la coincidencia entre sujeto del enunciado y de la enunciación se muestra inalcanzable y eternamente desplazada por la fracción más pequeña del instante. El tiempo, si bien no es mencionado, opera allí como la fuerza de disgregación que, fatalmente entendido, obliga al sujeto a velarse continuamente. El diario, en algún sentido, es un duelo que sucede de forma contemporánea a la cotidiana muerte de su escribiente. No parece irrisorio suponer que también constituya la modesta celebración del renacimiento. Es inevitable recordar el poema 11 de Árbol de Diana: "yo y la que fui nos sentamos/ en el umbral de mi mirada" (Pizarnik, Poesía completa 113). El sujeto 
construido por Pizarnik, tanto en el poema como en el diario, no logra anclarse dentro de un presente que lo estabilice y, en cambio, el deseo y la nostalgia, fundidos en el lenguaje, lo habilitan a un continuo movimiento fuera de sí mismo.

Por último, el mecanismo de la ambigüedad pronominal se encuentra en íntima relación con la alusión a las personas, pero se lo tratará por separado debido a la importancia que reviste. La ambigüedad pronominal sirve de hilo conductor para todos los mecanismos gramaticales explicados. El uso de pronombres de cualquier tipo -personales, posesivos, demostrativos, etc.-, así como su atribución a veces indebida, crea contrapuntos interesantes que desafían la integridad del sujeto que se ha querido cuestionar desde el comienzo. Por ejemplo: “¿Quién me busca desde mi mirada? ¿Quién me asfixia desde mis dos manos?" (Pizarnik, Diarios 441). En ambas preguntas, el pronombre reflexivo y el posesivo generan una aliteración con el sustantivo final de la frase: mirada/manos. El uso de los pronombres causa ambigüedades semánticas, puesto que la buscada encuentra a quien la busca en la mirada de aquella, la asfixiada advierte que quien la asfixia lo hace con las manos de aquella. Así, dos individuos, mutuamente necesitados -buscadora/buscada, asfixiadora/asfixiada-, se superponen en el cuerpo del sujeto, cuerpo percibido como espacio de encuentro y de pasaje, mientras que el pronombre interrogativo impide que se afiance una identificación total. De otra manera, el yo no preguntaría "quién», sino que hubiera dicho quizás: me busco desde mi mirada; me asfixio desde mis dos manos.

Finalmente, la entrada del 9 de enero de 1961 contiene uno de los usos de pronombres más arriesgado y ambiguo: "Me presenté: te doy, te soy" (Pizarnik, Diarios 1074). El "te» en "dar» es gramaticalmente correcto, en la medida en que designa un objeto indirecto. La interpretación podría ser: en el momento de presentarse uno da al otro lo que uno es. No obstante, con el verbo "ser», un complemento de objeto indirecto sería incorrecto. Para una posible interpretación, se podría recurrir a una construcción latina que perdura hasta hoy: el dativo de interés. Al presentarme, te doy a vos lo que yo soy y soy para vos en tanto que me presento como aquella que soy. Las licencias pronominales son habituales en Pizarnik y crean este tipo de ambigüedades interpretativas que cuestionan el posicionamiento del sujeto. Existe una voluntad explícita de confundir las personas, mientras que en la sombra siempre se encuentra una voz mutante y huidiza, que elabora de forma permanente su propio lugar de enunciación. 


\section{Figuras de la otredad}

Los mecanismos explicados en la sección anterior son recursos lingüísticos con los que la voz traza en el plano del sentido las distintas figuras que se desarrollarán en esta sección. Estas figuras son modulaciones de la voz del diario, formas medianamente constantes -topoi- de la expresión de su identidad. Sobre las estrategias gramaticales ya señaladas se erige el plano propiamente semántico.

El primer topos que aparece repetidas veces mencionado por Pizarnik es el doble y el espejo. Este último es un elemento privilegiado porque su funcionamiento ofrece al individuo un artilugio no por cotidiano menos increíble: acceder al rostro propio. De otra manera, nunca podríamos ver cómo son nuestros labios o nuestros ojos, exceptuando la superficie del agua que también es un espejo. Desde luego, esta transacción tiene un costo, el espejo nos impone una condición: vernos al revés, mover la mano derecha, pero que el espejo nos salude con la izquierda. En el fondo de la mímesis, anida una modificación. Un sábado de 1958 Pizarnik escribe: "De allí mi imposibilidad de comunicación con los otros. Ando en busca de esa mano, de esos labios... Y no es posible encontrarlos. Y aunque los encontrara nada sería posible, porque me da horrenda vergüenza sentir esto que siento mientras el espejo certifica una muchacha de veintiún años, devorada por la irrealidad" (Diarios 227).

Una primera interpretación llevaría a advertir, en la mención de «mano» y «labios», atributos y metonimias usuales para el objeto amoroso, un intento por definir un "otro» amado y no encontrado. La inclusión de adjetivos demostrativos de lejanía media - "esa», "esos»- hace emerger inmediatamente las fuerzas del deseo y del anhelo. Este alguien buscado tiene relación con el propósito salvífico del diario ubicado para Pizarnik en un anónimo destinatario. El amor es otra forma del espejo. La pulsión amorosa, no obstante, se encuentra frustrada en Pizarnik y el espejo tan solo muestra, en una desesperante tautología, otra igual a ella misma. La realidad del amor es reemplazada por una imagen de sí. Otra interpretación, en cambio, puede llevarnos a considerar que Pizarnik habla de su propia mano y sus propios labios. La imagen que le arroja el espejo sigue siendo ella misma, solo que atravesada por otro tipo de decepción: ser la que es, en lugar de la que quisiera.

El espejo, en paralelo con el diario, sirve a la persona escritural como método de constatación o certificación de su apariencia y, ulteriormente, de su propia identidad. Se alude a una tercera persona, "una muchacha de veintiún años», que es tanto Pizarnik como aquella 
que mira desde el otro lado del cristal (barrera infranqueable, no distinta de la hoja en blanco). Tanto el espejo como el diario nos revelan a nosotros mismos, pero para lograrlo deben crear un otro que, alejado de nosotros, permita nuestra contemplación. Al alter ego hecho de luz, Pizarnik lo describe como «devorada por la irrealidad», juicio que por propiedad transitiva debe referir a ella también. De igual manera, el alter ego hecho de palabras corre el peligro de perderse en la refracción infinita y lucha contra la tentación autodestructiva del análisis de sí. Este otro lingüístico es copia y producto de Pizarnik en cuanto que autora implícita de su diario. El lenguaje, que funciona como un estanque donde observar nuestros actos y pensamientos, no deja de ejercer la tentación de su capacidad figurativa. El diarista íntimo se parece a Narciso, que murió por no comprender que traficaba con una imagen. El espejo y el diario, comprendidos como sistemas contradictorios de ilusión y desvelamiento, han sido capaces de generar tanto admiración como miedo. Admiración, por cuanto revela lo oculto, y miedo, por cuanto lo oculto es traído a la conciencia, o, peor aún, porque lo oculto quizás no sea más que un sistema de imágenes reproducible y replicable ad infinitum, con lo que se obtiene la forma de un laberinto o un rizoma. Pese a avanzar linealmente en el tiempo, las entradas se ramifican, complejizan y repiten en términos de contenido, puesto que no hay uniformidad en el terreno de lo íntimo.

En relación con el miedo o la responsabilidad que pueden generar las revelaciones especulares, el siguiente ejemplo se muestra pertinente: "Me compré un espejo muy grande. Me contemplé y descubrí que el rostro que yo debería tener está detrás -aprisionado- del que tengo. Todos mis esfuerzos han de tender a salvar mi auténtico rostro. Para ello, es menester una vasta tarea física y espiritual" (Pizarnik, Diarios 250). El pasaje está teñido de cierto idealismo pesimista. La palabra «aprisionado» recuerda a San Agustín, que, igual que Platón, sostenía que el cuerpo era la cárcel del alma. El espejo denuncia que el mundo está hecho de sombras o simulacros, por lo que demuestra ser compatible con las filosofías idealistas. En Pizarnik el miedo aparece trastocado por la angustia: "Me dolía la memoria, me dolían los ojos, me dolía el espejo en que me miré" (Pizarnik, Diarios 1074). El espejo genera una distorsión y provoca la nostalgia de la identificación no lograda. Así lo observaba Lacan en su teoría sobre los estadios del espejo en la niñez. En la cita, el espejo deja ver un rostro falso y, gracias a eso, revela el verdadero. La operación, curiosa y hasta paradójica, es extrañamente coherente. El espejo, que es ficción, a través de una imagen, es decir, una mentira, manifiesta lo verdadero. De igual manera, el diario genera una imagen de la autora que no es idéntica a ella. No obstante, 
este simulacro, si bien implica una especie de falsedad, también puede ser un mecanismo de lo verdadero, es decir, el desocultamiento a través de lo otro.

El espejo adquiere diversas formas -por ejemplo, el estanque de Narciso-. La ventana es otra de ellas:

Son las 12 de la noche. Lo repito. Qué importa recomenzar antiguos hábitos nocivos si el dolor es el mismo, hoy que en el año 55. Y dentro de cuarenta años, si vivo -es un decir; pero espero no estar en esta "farsa imbécil"-, si vivo, repito, escribiré con mano temblorosa: "Son las 12 de la noche en mi augusta vejez solitaria. La noche está del otro lado de la ventana y yo, encerrada en una habitación vieja, polvorosa y mal iluminada. Me acuerdo de una noche del año 62 (creo que era el 28 de julio a las 24 horas): yo tenía miedo y para distraerme prefiguré mi vida: me imaginé en el año 2002 escribiendo en una pieza -vieja, polvorosa, y mal iluminada-: "la noche está del otro lado de la ventana, etc., etc."” (Pizarnik, Diarios 439).

El pasaje describe una puesta en abismo, es decir, el efecto de dos espejos enfrentados. Se creía, explica Cirlot, que el espejo era un objeto mágico y acortaba distancias, puesto que podía mostrar las cosas que había reflejado en el pasado o que reflejaría en el porvenir (194). Aquí la escritura primeramente iguala el dolor del año 1962 -presente de la enunciación- al de 1955, y luego pretende inmiscuirse en el futuro y adivinar lo que sucederá. En 2002, se escribe que la vida había sido prefigurada por el acto de escritura -vuelve la asimilación poeta/profetaejercido en el año 1962. Lo sucedido -el truco reside en la repetición de «son las 12 de la noche»; "la noche está del otro lado de la ventana»- rebota entre dos espejos tejidos con palabras. Sin embargo, tenemos un segundo espejo: la ventana, que funciona como portal introspectivo. En el pasaje, Pizarnik no comenta nada respecto del mundo exterior. La ventana es perfectamente opaca y sirve de dispositivo para que ella se adentre en su mundo interior de predicciones tortuosas.

La próxima figura que se analizará es la dislocación entre el sujeto y su voz o su cuerpo. En primer lugar, la voz que el sujeto usa para manifestarse muchas veces es percibida como extraña o ajena, una voz que llega, como la de las musas o la inspiración, desde un lugar innominado. Por otro lado, el cuerpo del sujeto se disgrega y multiplica al entrar dentro de la 
deriva del lenguaje. Ya no se tiene un cuerpo solo, sino tantos como sea posible enunciar o sentir.

El tema de la mirada es recurrente tanto en los diarios como en la poesía de Pizarnik, dado que sobre ella se apoyan algunas de las incógnitas cruciales de la poesía y del arte. El creador es quien busca mirar de una manera particular y hacer visible a los otros los objetos transfigurados por esa mirada. Contando lo que parecería una anécdota urbana, Pizarnik escribe: "Vi una vieja mendiga durmiendo en el suelo abrazada a una muñeca. (Yo no la vi. Mis ojos la vieron.)" (Diarios 1064). Por otro lado, el 24 de abril de 1963 hallamos un pasaje con fuertes reminiscencias de Edgar Allan Poe en el que se describen dos tipos de ojo (Pizarnik, Diarios 1084). Si bien la anatomía nos dice que contamos con un par de ojos iguales entre sí, la poeta reflexiona sobre la existencia de un ojo «presente» y otro «ausente». El primero es el "fiel testigo», es decir, el observador que mira las cosas objetivamente, tal cual son. Dicho así, esto es en realidad ambiguo, pues qué significa mirar las cosas tal cual son. Podría tratarse de mirar los objetos en cuanto que útiles, en cuanto que materia, o bien mirarlos de manera absoluta, igual que Dios es siempre testigo de la creación. Por otro lado, si el ojo fisiológico nos permite ver una faz de los objetos, ver todas las faces equivaldría a anularlas, pues el ojo entraña siempre un posicionamiento. Al "Ojo presente», ideal de un objetivismo sin contradicciones, Pizarnik contrapone otro «ausente» que se extravía luego de haber mirado. La realidad es usada como punto de partida para comprender otra realidad interior del sujeto, para rellenar ausencias y, en definitiva, para crear algo distinto. El ojo ya no es más un registro pasivo, sino una entidad activa. Así quedan englobadas las dos actitudes del poeta: el registro de/ mundo y la creación de un mundo, díada que en cierta forma replica la oposición fundamental entre realismo y romanticismo.

Para toda creación de orden lingüístico, son necesarias la palabra y la voz. Esta segunda es palabra subjetivada, dotada de la vida del pronunciamiento. La voz, que muchas veces se sitúa fuera de Pizarnik - "Obligación formulada por una voz lejana" (Pizarnik, Diarios 399)-, se encuentra en estrecha vinculación con el mito romántico. Pizarnik elaboró un marco conceptual de herencia romántica dentro del cual ser leída. En el diario, las musas están más que nada ausentes, dejan solo al sujeto o le envían incomprensibles dictámenes. De ahí que en Pizarnik sean la persistencia y la corrección obsesiva las encargadas de pulir la lengua para que llegue a la intensidad de la visión. 
Por último, la extranjería funciona como archifigura conceptual que engloba las figuras del espejo y la dislocación sujeto-voz-cuerpo. La voz del discurso construye una subjetividad marcada por la errancia, por la carencia de origen, embarcada en búsquedas inciertas y penosas, a disgusto con los lugares que ocupa:

Dicen que mi sangre es europea. Yo siento que cada glóbulo procede de un punto distinto. (...) De cada trozo de tierra o de mar han usurpado algo y así me formaron, condenándome a la eterna búsqueda de un lugar de origen. (...) Heredé el paso vacilante con el objeto de no estatizarme nunca con firmeza en lugar alguno. ¡En todo y en nada! ¡En nada y en todo! (Pizarnik, Diarios 57-58).

Escribir un diario es una actividad contradictoria. Por un lado, define y ancla un momento de la subjetividad en la escritura y, por otro, debido a su dinámica de entradas diarias, a su imantación sobre la línea temporal en perpetuo desarrollo, convierte la palabra en una forma de errancia. Quien escribe descubre al cabo del tiempo que no es idéntico a sí mismo, ya que la identidad no es una categoría inmóvil. La apertura del yo al discurso engendra en el seno de la escritura diarística una perpetua producción de significantes y significados, y, por ende, la carencia absoluta de eje. El desarraigo está implicado en lo poético: surge como "consecuencia inevitable de la distancia entre significado y significante" (Di Ció 3), que a su vez pone en movimiento la actividad imaginativa. Di Ció plantea que todas las figuras femeninas de Árbol de Diana -podríamos hacer extensivo el comentario a las del diario- "remiten a un sujeto descentrado, a alguien que no está en su lugar allí donde está y que, por ello mismo, se proyecta en la disidencia y la marginalidad, literal o metafórica" (4). Así, se explican "las representaciones marginales o avatares del escritor, como pueden serlo la figura del errante o nómada y la figura del poeta inspirado o escritor maldito" (3). La escritura del diario representa un tipo de errancia y Pizarnik, específicamente, pone en acto dentro de su texto un sujeto deliberadamente descentrado que se conecta con el poeta maldito, en cuanto que sujeto histórico e historiográfico.

En el diario de Pizarnik, la voz del discurso funda una figura autoral que puede ser descripta de la siguiente manera: un sujeto femenino marginal, que vive el ideal de la bohemia, sometido a los mandatos del arte, sin claudicaciones de ningún tipo, que se rebela a las prescriptivas sexogenéricas, que no cede ante la sociedad normalizante y que, por lo tanto, 
adquiere la condición de una nómada a la espera de alucinaciones. Este montaje textual, en tanto que es buscado, no tiende a disminuir su figura producto de asimilaciones patéticas, sino a enaltecerla. Di Ció lo entiende de la siguiente manera:

Estamos, entonces, ante un sujeto que busca autolegitimarse mediante la reafirmación de su posición marginal y, paradójicamente, en ese mismo movimiento busca -y encuentra- una filiación literaria y simbólica que le da prestigio. En otras palabras, construye una figura de escritor que se quiere marginal, maldito, pero que no deja de apuntar, ni de estar en, la centralidad del canon (7).

Pizarnik fue lectora y admiradora de los llamados «poetas malditos». El origen del término se remonta a Paul Verlaine, que publicó un libro homónimo en 1894 con ensayos sobre diversos poetas de la época. Algunos de ellos pasaron a la historia (Rimbaud, Verlaine, Mallarmé) y el término adquirió un uso extensivo, pues llegó a emplearse para otros poetas que comenzaron a formar parte de un mismo árbol genealógico. Pizarnik, que quiso pertenecer a esta familia dispersa de descarriados, se construyó textualmente en esa dirección.

\section{Las fuerzas de lo verosímil}

Al comienzo del trabajo, se analizó la fisonomía del "sujeto disperso» de Pizarnik dentro del diario. Para ello, fue necesario enumerar y revisar cuatro procedimientos gramaticales deícticos de los que se vale el sujeto para construir su descentramiento. También, se explicaron tres figuras repetidas a lo largo del diario y que revelan o manifiestan este descentramiento. El sujeto pizarnikiano dentro del diario es diverso y uno a la vez. De esa diversidad hemos ofrecido pruebas. Sobre su condición de uno basta decir que siempre podemos recurrir al nombre propio: Flora/Alejandra Pizarnik, palabras que resultan tan tranquilizadoras como ambiguas, pues cimientan la siguiente ilusión referencial: Pizarnik -sujeto biográfico-/Pizarnik -sujeto escribiente-/Pizarnik - sujeto textual-. Sin embargo, todas estas personas son distintas y están actuando sobre el texto. Pizarnik al escribir sobre ella impone una distancia discursiva que le permite rearmarse como objeto textual del otro lado de la hoja en blanco. El lector recibe un sujeto del diario que en realidad supone estas tres entidades. Por otro lado, Pizarnik pone en acto la imposibilidad de definirse a ella misma como sujeto único anclado en categorías 
identitarias estables (ubicación, tiempo, fisonomía, etc.), que, en cambio, se revelan siempre provisorias. No es posible conocer ninguno de esos datos con absoluta precisión sin alterar el conjunto de lo que se percibe como identidad. Afirmaremos, por consiguiente, que dichas variables que componen una subjetividad solo pueden ser aprehendidas a través de un esfuerzo, nunca todas a la vez y siempre a través de un lenguaje que modifica al mismo tiempo que pretende describir.

Parece oportuno recordar el concepto de paratopía de Dominique Maingueneau que Di Ció utiliza en su artículo. La paratopía es definida como el lugar alternativo que surge de las transacciones entre el lugar y el no lugar. Esta ubicación se sostiene en su incapacidad de encontrar un punto de reposo. Lo que antes era una vacilación, una interferencia, una suerte de hibridación espacial, ahora, con el nombre paratopía, se convierte en un objeto teórico identificable en su falta de estabilidad. Aplicado a Pizarnik, este concepto "no solo es compatible con las tensiones que desencadenan estas tortuosas duplas (vida/obra; individuo/sociedad o individuo/campo literario) -que no pretende resolver-, sino que, precisamente, es a partir de estas tensiones, de esa inestabilidad, de esa oscilación, que se construye la obra" (Di Ció 2). En la escritura autobiográfica, la negociación paratópica se presenta en el nivel de la escritura y en el de la lectura, tal como había advertido Paul de Man (921). Por otro lado, toda escritura de sí no es únicamente discurso, enunciado muerto sobre una realidad muerta, sino un acto performativo que resuena en el sujeto y lo altera.

La física cuántica, como ya fue mencionado, puede ofrecer un modelo comparativo de ayuda: la paradoja de Schrödinger. Ella explica lo siguiente: un gato, al que se le ha dado una ampolla frágil de cianuro, es puesto dentro de una caja negra con una carga radioactiva. La emisión de partículas subatómicas puede romper la carga venenosa dentro del gato o no. Hay cincuenta por ciento de probabilidades de que la carga se libere y el gato muera, o de que no se libere y el gato viva. Hasta que no abramos la caja, no sabremos si el gato está vivo o muerto. La paradoja sirve de explicación para dos principios de la física cuántica: el principio de superposición y el de incertidumbre (The Uncertainty Principle). Para el primero, en estado cuántico, sin realizar mediciones, el gato está vivo y muerto al mismo tiempo. El observador, en cambio, altera el sistema, modifica la realidad y al abrir la caja hace que el gato adopte uno solo de esos estados. Por otro lado, según el principio de incertidumbre, no se pueden conocer un par de variables dentro de un sistema con absoluta precisión. Al medir una, la otra se modifica 
en sentido opuesto. Cuanto más seguro estoy del valor de la posición de un electrón, es igual de grande el desconocimiento acerca de la cantidad de movimiento que tiene esa partícula. Esto sucede porque la medición de una de las magnitudes conlleva la alteración de la otra. Para la realidad cuántica dentro de la caja de la paradoja, el gato está en ambos estados al mismo tiempo, mientras que para la realidad del observador el gato debería estar o vivo o muerto. El observador no puede saberlo, ya que en el momento en que abra la caja su observación modificará al gato que pasará de vivo/muerto a uno solo de esos estados observables. De esta manera, aplicando la misma lógica, el sujeto del diario es víctima de su propia incertidumbre cognoscente, pues todo acto en pos de conocerse solo modifica la estructura cognoscible. Lo que el sujeto cree que llega a asir no es más que un pasado inmediato de sí mismo creado en el lenguaje. Querer asirse es, luego, no asirse nunca, ya que dicha acción perturba el sistema. De esta manera, se engendra el mecanismo del deseo en el seno de la intimidad y se inaugura un círculo sin fin de escritura y frustración que le otorga al diario su vida pertinaz. Este movimiento encuentra armonía en la estructura recursiva de las entradas. El escritor, en definitiva, enfrentado a la hoja en blanco, solo podrá articular un discurso paratópico, en cuanto negociación entre lo que puede conocer de sí, lo que puede expresar de sí, lo que finalmente crea de sí y las restricciones que se impone respecto del lector ideal de su texto. No hay univocidad posible, por mucho que se anhele.

A nivel de la lectura sucede algo similar. El lector tendrá que negociar -si no, en última instancia, decidir- qué cree de lo que el sujeto, en este caso Pizarnik, le cuenta de su vida. El diario, que los lectores en general presuponen sincero - en oposición a la mentira pactada que suele ser la literatura-, puede -y de hecho lo hace- incurrir en la mentira, voluntaria o no, o en esa forma más sutil de la mentira que es la exageración. Permanece en las sombras cuánto de lo que leemos está en relación con la vida del autor y cuánto responde a las exigencias de una producción puramente textual. Dentro de esta polaridad imprecisable se mueve el diario y es una de las razones por las que despierta renovado interés. El lector ejerce sobre el discurso íntimo la sustitución recíproca que Paul de Man (921) puso en evidencia. Probablemente sea este rasgo, junto con los criterios formales que esbozó Lejeune (El pacto autobiográfico... 48), el que nos permita hablar de una familia de géneros autobiográficos, siempre haciendo la salvedad de que De Man trabajó específicamente sobre el subgénero autobiografía y lo imaginaba un modo de lectura más que un género. El procedimiento de sustitución recíproca 
está por un lado presidido y avalado por el nombre propio, por cuanto dirige la lectura e induce a una ilusión que De Man buscaba desmontar. En la medida en que el lenguaje es de naturaleza trópica, este no puede ser confundido con la realidad que representa. Discurso y realidad jamás coinciden. El diario solo es el lugar donde parece que ambas esferas están más cerca.

El sujeto de Pizarnik se manifiesta en el texto de manera heterogénea construyendo esa identidad dispersa que se ha buscado probar y esbozar a lo largo del artículo. El sujeto, en su búsqueda de autorrepresentación, día a día, deja marcas sobre la hoja en blanco que le permiten establecer un esbozo de su propia subjetividad, que no es única ni puede aprehenderse totalmente. Pizarnik anota con paciencia lo que encuentra en un territorio inestable y cambiante, como si anotara la posición de las dunas en un desierto. Dos preguntas no menores hacen su aparición: ¿cómo puede el relato del diario mantener la consistencia a merced de semejante heterogeneidad? y ¿cómo es posible que la productividad inherente a la intimidad no destruya la coherencia interna del diario? La respuesta a la que esta investigación ha llegado es la siguiente: a través de las fuerzas de lo verosímil.

En Semiótica //, Kristeva expone lo siguiente:

lo verosímil (el discurso "literario") es un grado segundo de la relación simbólica de semejanza. Siendo el auténtico querer-decir (husserliano) el querer-decir-verdadero, la verdad sería un discurso que se asemeja a lo real; lo verosímil, sin ser verdadero, sería el discurso que se asemeja al discurso que se asemeja a lo real (11).

Invocando la negociación de lo paratópico, el diario se muestra como un género entre estos dos discursos: entre lo que quiere ser -la verdad- y lo que es - un texto literario verosímil o verosimilizado-. Sobre el diario pesa, como aducía Lejeune, el discurso de lo verdadero (On Diary 203). No obstante, no deja de regirse por las reglas del discurso literario, ni de querer construirse como texto autónomo, más allá de su correspondencia con una referencia externa, y, por cuanto no copia lo real, sino que expone la productividad íntima, no puede ser juzgado únicamente- por su grado de «verdad». Ningún diario puede ser leído a la luz de su comprobación extratextual, pues perdería su belleza expresiva y estética, así como su ambigüedad. Se tornaría un mero documento, tan solo un registro, función que también hasta cierto punto desempeña. Si toda obra, como argumenta Di Ció a partir de Maingueneau, surge 
de la transacción entre lo biográfico y el espacio literario (3), entonces el diario se convierte en el grado cero de este suceso, el momento en el cual ambos planos pueden verse, si bien no sean cuantificables ni deslindables.

Otra pugna se cierne sobre el diario: entre la productividad íntima y la voluntad verosimilizante. Kristeva escribe:

Unido a la productividad textual, el concepto de "indecidible" implica que el procedimiento escritural (el trabajo textual, el pensamiento en marcha) es ajeno a los conceptos de prueba y de verificación. Ahora bien, ¿qué es lo verosímil sino la posibilidad implícita a todo sistema monomórfico de probar y de verificar? La "verdad" de la productividad textual no es comprobable ni verificable, lo que querría decir que la productividad textual depende de otro terreno que el de lo verosímil (50).

Si se considera la intimidad como el lugar del engendramiento y el engendramiento a la vez, su verdad está, como dice Kristeva, en "el cumplimiento del gesto productivo" (50), por lo que no busca crear un estatuto a través del cual los elementos del proceso que lleva a cabo puedan adquirir verificación mutua. Tampoco está la intimidad en relación con un contenido anterior a sí misma. El diario, sin embargo, establece una estructura verosimilizante que encausa la productividad y le ofrece una arquitectura que la contenga. A la productividad íntima es necesario darle el mito de una esencia, aun cuando esta sea ficticia. Si todo texto entraña su propia verosimilitud, Pizarnik hace lo suyo con el diario. Es necesario, para decirlo bruscamente, que sea inteligible/legible, pues en la inteligibilidad/legibilidad está implícita la coherencia. Así, al menos se comprende aquí lo que Kristeva denomina por verosímil: "El efecto verosímil es un efecto de isomorfismo entre dos estructuras discursivas (estructura literaria-estructura del enunciado comunicativo) en el interior de esa red de axiomas lógicos monomórficos que es nuestro sistema de inteligibilidad" (48). La verosimilitud es un efecto que se consigue a través de la referencia anafórica, toda vez que la productividad textual, por ser un mecanismo, tiende a destruir "la identidad, la semejanza, la proyección identificatoria; es una no-identidad, una contradicción en funcionamiento" (47). En Pizarnik se hallan los dos registros: el de la productividad íntima, que disgrega el sujeto que supuestamente presupone y construye, y el de la verosimilitud, que amalgama y estructura dentro de lo inteligible al sujeto en el borde de la disgregación productiva. 
Contrapuesta al diario, la autobiografía es un género absolutamente verosimilizante. Ella intenta darnos la ilusión de una vida concretada, aun cuando el individuo que escribe está vivo y continúa escribiendo. De ahí que Paul de Man conectara este género con la pulsión de muerte y la figura de la prosopopeya. El diario, en cambio, es un género no conclusivo, pues puede escribirse en tanto se tenga otro día por delante. Está imbricado en el tiempo vital de quien lo escribe, a diferencia de la autobiografía, en la que el autor se narra como quien busca legar un extenso epitafio. El diario, por el contrario, se mueve sobre una doble vertiente: la productividad íntima de la significancia y la tarea de generar el efecto de verosimilitud de dicha vida.

De los siete procedimientos revisados, los que fueron denominados mecanismos gramaticales deícticos, que actúan al nivel de la estructura de la lengua y aplican a ella su combinatoria, sancionan la productividad íntima en el seno de Diarios. Pese a esto, las entradas no desbordan en una confusión incomprensible de referencias inconexas. Los personajes, las segundas o terceras personas, los pronombres, siempre hacen referencia a un sujeto femenino descentrado. Aquí es cuando se gesta el efecto de verosimilitud, que da al lector y a sus estructuras lógicas una forma comprensible, a la vez que el texto construye su propia figura autoral. Los otros tres procedimientos, que obran en el nivel del sentido, buscan rearmar dentro de la heterogeneidad productiva el efecto verosímil del descentramiento, del sujeto joven e incomprendido, de la marginalidad, etc. La productividad íntima genera una subjetividad errática, móvil y dislocada. El criterio de verosimilitud homogeneiza las referencias e invoca una coherencia textual dentro de la disgregación. Solo de esta manera puede el diario subsistir. Verosimilitud y productividad se necesitan mutuamente, ya que cada una asegura la continuidad de la otra.

En conclusión, el sujeto se construye dentro del diario continuamente en la pugna productividad/verosimilitud. El primer movimiento tiende a la dispersión, el segundo a la autocontención. La denominación "sujeto disperso» se revela más pertinente a la luz de este planteamiento. Dentro del espacio íntimo, el yo de Pizarnik vive en un estado de indeterminación por hipertrofia, pluridimensionalidad del cuerpo, facetado del rostro. Sin embargo, esta discursividad convulsa, a instancias de la voluntad de autorrepresentación, deviene escritura y comienza a moldearse dentro de una forma verosímil. Así, se crea no solo el efecto de lo verosímil, sino la norma de verosimilitud por la que hay que juzgar al texto. Cada acto de escritura en el diario, es decir, cada entrada, supone una manifestación individual convertida al 
código de lo verosímil. Es un momento de ese sujeto disperso, puesto que el diario destruye la homogeneidad del tiempo real para recuperar en el plano discursivo el instante pleno. Este sujeto, sustentado por el ambiguo pronombre de primera persona, se atrinchera en el sintagma: "Yo escribo que..... El pronombre de primera persona es la única entidad que se mantiene estable a lo largo del diario, punto ciego de la representación y, a la vez, eje de todo lo representado. Ese personaje que escribe el cuaderno es oscuro, impenetrable, pero existe, está siempre presente: "Pensé que, teniendo la máquina de escribir, ya no necesitaría más estos morbosos cuadernillos" (Pizarnik, Diarios 67); "este yo que está escribiendo ahora" (Pizarnik, Diarios 118). Lo que el lector pueda fabricarse de ese yo nacerá de la negociación entre la productividad íntima y la verosimilitud impuesta por la obra y la voz de Pizarnik, o entre la verdad

y la semejanza de la verdad, contienda (paratópica) indefinible que sustenta una localización y una definición ambiguas del sujeto. Si bien presente en muchos lugares, el sujeto no está en ninguno en su totalidad. Su naturaleza es indeterminada, apenas estimable por la acumulación de sus otras apariciones.

\section{Referencias}

Aira, César. Alejandra Pizarnik. Rosario: Beatriz Viterbo, 2012. Impreso.

Arfuch, Leonor. El espacio biográfico. Dilemas de la subjetividad contemporánea. Buenos Aires: Fondo de Cultura Económica, 2010. Impreso.

Bajtín, Mijaíl. Estética de la creación verbal. México: Siglo XXI, 2008. Impreso.

Barthes, Roland. "Deliberación”. Lo obvio y lo obtuso. Barcelona: Paidós, 1986. 365-380. Impreso.

Benveniste, Emile. Problemas de lingüística general. México D. F.: Siglo XXI, 1997. Impreso.

Blanchot, Maurice. "El diario íntimo y el relato". El libro que vendrá. Caracas: Monte Ávila, 1959. 207-212. Impreso.

Buenaventura, Sandra et al. "El sujeto AP genera identidades infinitas. Un análisis informatizado de los Diarios de Alejandra Pizarnik". Alejandra Pizarnik: el lugar donde todo sucede. Eds. Milagros Ezquerro y Adelaide Chantellus. París: L'Harmattan, 2013. 243-256. Impreso.

Cantero Sanchez, Mayte. "Cómo ser poeta (y no) morir en el intento: La construcción autorial en los diarios de Alejandra Pizarnik". Escribir como mujer: ¿hacia una reescritura de la 
autoría? Eds. Aránzazu Calderón Puerta et al. Varsovia: Instituto de Estudios Ibéricos e Iberoamericanos de la Universidad de Varsovia, 2017. 219-231. Impreso.

Catelli, Nora. "Invitados al palacio de las citas - Los diarios inéditos". Clarín. Cultura y Nación. 14 sept. 2002. 5. Impreso.

Catelli, Nora. En la era de la intimidad. Rosario: Beatriz Viterbo, 2007. Impreso.

Cirlot, Juan Eduardo. Diccionario de símbolos. Barcelona: Labor, 1992. Impreso.

De Man, Paul. "Autobiography as De-facement". MLN. 5 dic. 1979: 919-930. Impreso.

Di Ció, Mariana. "Paratopía, localización y género en la obra de Alejandra Pizarnik”. XVI Congreso de la Asociación Internacional de Hispanistas, París, 8-13 de julio 2007. 1-9. Inédito.

Foucault, Michel. Tecnologías del yo. Buenos Aires: Paidós, 2008. Impreso.

Giordano, Alberto. "Notas sobre diario de escritores". Alea. Sept-Dic. 2017: 703-713. Impreso. Hilgevoord, Jan y Jos Uffink. "The Uncertainty Principle". The Stanford Encyclopedia of Philosophy (Winter 2016 Edition). Ed. Edward N. Zalta. Web. $<\underline{\text { https://plato.stanford.edu/archives/win2016/entries/qt-uncertainty/ }>}$

Kristeva, Julia. Semiótica I/. 2a ed. Madrid: Fundamentos, 1981. Impreso.

Lejeune, Philippe. "El pacto autobiográfico". Suplementos Anthropos. 29 dic. 1991: 47-61. Impreso.

Lejeune, Philippe. On Diary. Hawái: University of Hawai'i Press Books, 2009. Impreso.

López, Czarina Lagarda y Rosa María Burrola Encinas. "Estrategias de autorrepresentación en Alejandra Pizarnik". Connotas. 16. 2016: 157-173. Impreso.

Percia, Violeta. "Una inédita manera de esperar". Marca de agua. 1. 2. Abr. 2017: 84-87. Impreso.

Pizarnik, Alejandra. Diarios. Buenos Aires: Lumen. 2016. Impreso.

Pizarnik, Alejandra. Poesía completa. Buenos Aires: Lumen, 2000. Impreso.

Premat, Julio. Héroes sin atributos: figuras de autor en la literatura argentina. Buenos Aires: Fondo de Cultura Económica, 2009. Impreso.

Ricoeur, Paul. Sí mismo como otro. Ciudad de México: Siglo XXI, 1996. Impreso.

Rocco, Federica. "Alejandra Pizarnik: de la desintegración del sujeto a la multiplicación infinita". Altre Modernità. 17 may. 2017: 82-93. Impreso. 
Rocco, Federica. "Los Diarios de Alejandra Pizarnik. El loco afán por (re)escribir(se)". Diarios latinoamericanos del siglo XX. Eds. Ana Gallego Cuiñas et al. Bruselas: P.I.E Peter Lang, 2016. 199-209. Impreso.

Rocco, Federica. "Los Diarios de Alejandra Pizarnik". Mujeres en el umbral. Coords. Emilia Perassi y Susanna Regazzoni. Sevilla: Renacimiento, 2006. 105-117. Impreso.

Rocco, Federica. "Errancia y nomadismo en la vida-obra de Alejandra Pizarnik". HispanisteS. 12. 2019: 201-210. Impreso. 